\title{
DETERMINAÇÃO DAS PROPRIEDADES FUNCIONAIS DE CARNE MECANICAMENTE SEPARADA (CMS) DE TILÁPIA DO NILO (Oreochromis niloticus) ANTES E APÓS O PROCESSO DE HIDRÓLISE ENZIMÁTICA
}

\author{
A. P. KEMPKA ${ }^{1}$, A. Z. DINON ${ }^{1}$, H. F. BATTISTELLA ${ }^{1}$, V. D, HEIZEN ${ }^{1}$ e R. C. PRESTES ${ }^{2}$ \\ ${ }^{1}$ Universidade do Estado de Santa Catarina, Departamento de Engenharia de Alimentos \\ ${ }^{2}$ Universidade Federal de Santa Maria, Departamento de Tecnologia e Ciência dos Alimentos \\ E-mail para contato: aniela.kempka@udesc.br
}

\begin{abstract}
RESUMO - O presente estudo verificou as propriedades funcionais hidrofílicas da CMS de Tilápia bruta e seca, não hidrolisada e hidrolisada enzimaticamente utilizando-se a enzima Flavourzyme ${ }^{\circledR}$. Primeiramente fez-se a caracterização físico-química da CMS, fracionamento e secagem das amostras a $60^{\circ} \mathrm{C}$ sendo, posteriormente, determinadas a solubilidade e a capacidade absorção de água (CAA) em diferentes pHs (3, 5, 7 e 11) e capacidade de retenção de óleo (CRO) e parâmetros de cor, antes e após a hidrólise. O Grau de Hidrólise (GH) foi determinado ao longo de 360 minutos. Os resultados do GH apresentaram diferença estatística significativa $(\mathrm{p}<0,05)$ para os tempos de 60 minutos e 300 minutos, correspondendo a 33,95\% e 58,98 \%, respectivamente. Para a solubilidade, apenas a amostra hidrolisada durante 300 minutos e em pH 11 apresentou diferença significativa. Para a CAA, nos pHs 5 e 11, houve diferença entre as amostras controle e os hidrolisados. Para uma mesma amostra, verificou-se que o controle apresentou diferença na CAA para os pHs 3-5 e os pHs 7-11. Para o hidrolisado durante 60 minutos não houve diferença estatística e para os hidrolisados durante 300 minutos, a CAA em pH 11 apresentou diferença significativa, sendo obtida, nestas condições, o maior valor, correspondente a $317,84 \%$. Para a CRO, não houve diferença entre as amostras. Quanto aos parâmetros de cor, apenas $\mathrm{a}^{*} \mathrm{e} \mathrm{b}^{*}$ apresentaram diferença significativa entre $\mathrm{o}$ controle e os hidrolisados, sendo os últimos com valor superior.
\end{abstract}

\section{INTRODUÇÃO}

A Tilápia (Oreochromis niloticus) é uma espécie cultivada no Brasil desde 1971 (Maia, 1992). Apresenta requisitos típicos dos peixes preferidos do consumidor, tais como carne branca de textura firme, sabor delicado e fácil filetagem, não tendo espinha em "y" e nem odor pronunciado (Souza, 2002). Possui também características que a classificam como uma das principais espécies cultivadas comercialmente, como: facilidade de reprodução e obtenção de alevinos (Simões et al., 2007). Quanto ao valor nutricional, o pescado, incluindo a Tilápia, pode ser considerado uma excelente fonte de minerais fisiologicamente importantes, tais como, 


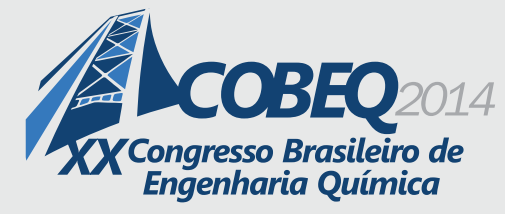

magnésio, manganês, zinco, cobre, dentre outros, com conteúdos relativamente elevados. O músculo esquelético do pescado é rico em proteínas e lipídeos (Ogawa e Maia, 1999).

Mesmo sendo uma excelente fonte nutricional, o aproveitamento total do pescado ainda é algo a ser explorado e incorporado na indústria. Geralmente, a Tilápia passa pelo processo de filetagem, sendo, na grande maioria das vezes, o restante da carcaça descartado como resíduo. Segundo Chalamaiah (2012), a indústria de processamento de peixe produz mais de $60 \%$ de subprodutos como resíduos, que inclui a cabeça, pele, nadadeiras, frames, vísceras e ovas, e apenas $40 \%$ de produtos de pesca para consumo humano. São considerados resíduos de pescado as carnes escuras, peixes de baixo tamanho comercial, resíduos obtidos dos processos de filetagem, cabeça, carcaças e vísceras (Visentainer et al., 2003). Os resíduos provenientes de frigoríficos processadores de peixe, principalmente de filetagem de Tilápia representam $62,5 \%$ a 66,5\% da matéria-prima (Boscolo et al., 2001).

No Brasil, o aproveitamento de resíduos da industrialização de pescado é considerado baixo, destinando-se, principalmente, ao preparo de farinhas de pescado. A transformação destes resíduos em produtos para alimentação humana é uma ótima opção de renda para as indústrias, podendo aumentar sua lucratividade através do uso de equipamentos capazes de separar o material muscular agregado às espinhas com facilidade. $\mathrm{O}$ material muscular resultante é conhecido como carne mecanicamente separada (CMS) (Vidal et al., 2011).

Dentre os produtos que podem ser obtidos a partir da proteína existente na CMS de Tilápia estão os hidrolisados proteicos. A hidrólise das proteínas de pescado usando enzimas proteolíticas possibilita o controle do grau de clivagem das proteínas no substrato. A utilização de proporções adequadas de enzima/substrato e tempos específicos de reação permite a produção de hidrolisados com diferentes propriedades funcionais que podem encontrar aplicações em várias formulações alimentícias (Santos et al., 2009). A hidrólise pode alterar as propriedades das proteínas de três formas: diminuindo a massa molecular, aumentando o número de grupos ionizáveis e causando a exposição de grupos hidrofóbicos. Essas interações controlam as propriedades físico-químicas das formulações alimentares (Panyam e Kilara, 1996). A modificação da estrutura da proteína pela hidrólise enzimática é empregada com o intuito de modificar as propriedades funcionais (Zavareze et al., 2009).

Diante disto, o presente estudo teve como objetivo verificar as propriedades funcionais hidrofílicas de CMS de Tilápia do Nilo antes e após a hidrólise enzimática sendo determinadas a solubilidade e a capacidade de absorção de água em diferentes pHs, a capacidade de retenção de óleo e a cor.

\section{MATERIAL E MÉTODOS}

A CMS de Tilápia do Nilo foi fornecida pela Cooperativa de Produção, Industrialização e Comercialização Edson Adão Lins (COOPEAL), localizada na cidade de Abelardo Luz - Santa Catarina. 


\subsection{Caracterização Físico-química da CMS in natura e secagem da CMS}

Na caracterização físico-química determinou-se, em triplicatas, o pH, a acidez, a umidade pelo método de secagem direta em estufa a $105{ }^{\circ} \mathrm{C}$, lipídios pelo método de Soxhlet, proteína pelo método de Kjeldahl, cinzas, sendo todas as metodologias de acordo com o Instituto Adolfo Lutz (2008). A atividade de água foi determinada utilizando-se Higrômetro Aw (Testo 650).

Amostras da CMS foram divididas em porções, acondicionadas em bandejas de alumínio e dispostas em estufa com circulação de ar a temperatura de $60{ }^{\circ} \mathrm{C}$ (IAL, 2008).

\subsection{Análise Elementar das Amostras de CMS Bruta e Desengorduradas}

A Análise Elementar (CHNS - Carbono, hidrogênio, nitrogênio e enxofre) das amostras bruta e desengorduradas foi realizada por combustão. Para obtenção dos valores de proteínas, multiplicou-se o valor do percentual de nitrogênio por 6,25 (valor de referência).

\subsection{Hidrólise Enzimática da CMS e Determinação do Grau de Hidrólise (GH)}

Para a hidrólise enzimática das amostras de CMS bruta e desengorduradas, prepararam-se dispersões em Erlenmeyers de $250 \mathrm{~mL}$ utilizando-se a CMS, tampão fosfato de sódio $100 \mathrm{mM}$ pH 7,0 e a enzima Flavourzyme ${ }^{\circledR}$. Para tanto, pesou-se uma determinada quantidade de CMS que correspondeu a uma concentração total de proteína em solução de $5,0 \%(\mathrm{~m} / \mathrm{v})$ e a enzima foi adicionada ao meio na concentração em relação à massa total de proteínas de $8,0 \%$ ( $\mathrm{g}$ de enzima/g proteína). Os Erlenmeyers foram dispostos em banho Dubnoff (SL 157-Solab) a temperatura de $50{ }^{\circ} \mathrm{C}$ e $50 \mathrm{rpm}$ de agitação, onde permaneceram por 6 horas. Retiraram-se amostras nos primeiros 30 minutos de reação e após, a cada 60 minutos, totalizando 360 minutos de reação. As alíquotas foram centrifugadas durante 10 minutos sendo utilizado o sobrenadante obtido para determinação do Grau de Hidrólise (GH). Todos os experimentos foram realizados em triplicata. O GH foi determinado utilizando-se a metodologia de Biureto (Schmidt e SallasMellado, 2009).

\subsection{Propriedades Funcionais Hidrofílicas}

Solubilidade: Para a obtenção da solubilidade, utilizou-se a metodologia de Liu et al. (2010) adaptada. Pesou-se 1,33 g de amostra que foi dispersa em solução tampão em diferentes pHs $(3,5,7$ e 11). As misturas foram agitadas em Shaker a temperatura ambiente durante 30 minutos e centrifugadas a $3.000 \mathrm{rpm} / 15$ minutos. Após, retirou-se o sobrenadante e determinouse o teor de proteína, sendo a solubilidade da proteína utilizando a relação: conteúdo de proteína

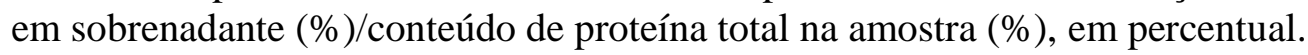

Capacidade de retenção de óleo (CRO): Para a determinação da CRO utilizou-se a metodologia de Wasswa et al. (2007). Pesou-se 0,5 g de amostra e adicionou-se $10 \mathrm{~mL}$ de óleo de soja (Soya) em um tubo de centrífuga. Procedeu-se a mistura durante 30 segundos a $100 \mathrm{rpm}$. A 


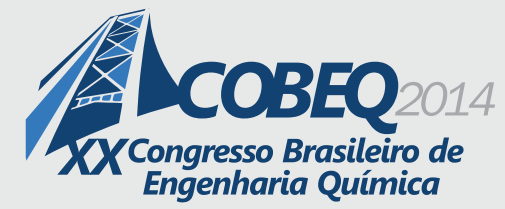

19 a 22 de outubro de 2014

Florianópolis/SC

dispersão de óleo foi centrifugada por 30 minutos/3.000 rpm. Determinou-se o volume de óleo separado sendo a CRO calculada como o $\mathrm{mL}$ de óleo absorvido/g de amostra de CMS.

Cor instrumental: A cor instrumental foi determinada utilizando-se equipamento Minolta ${ }^{\circledR}$ CR 310 (iluminante C ou D65 e ângulo $10^{\circ}$ ), obtendo-se os parâmetros de cor L* (luminosidade), $\mathrm{a}^{*} \mathrm{e} \mathrm{b}^{*}$ (coordenadas de cromaticidade).

Capacidade de Absorção de água (CAA): Utilizou-se a metodologia de Wang et al. (2006). Pesou-se $1,33 \mathrm{~g}$ da amostra de CMS sendo esta amostra adicionada a um tubo de centrífuga de 15 $\mathrm{mL}$ previamente pesado. Adicionou-se $8 \mathrm{~mL}$ de tampão em diferentes valores de $\mathrm{pH}(3,5,7 \mathrm{e}$ 11). Esta mistura foi agitada por 30 segundos. O conteúdo permaneceu em repouso por 10 minutos e, em seguida, foi centrifugado a $2.300 \mathrm{rpm} / 25$ minutos. O sobrenadante foi esgotado e o tubo colocado inclinado (ângulo de $15^{\circ}$ a $20^{\circ}$ ) em estufa com circulação de ar (Orion) a $50^{\circ} \mathrm{C}$, durante 25 minutos. Após o resfriamento do tubo, este foi pesado e a CAA calculada em relação a $100 \mathrm{~g}$ de amostra.

\section{RESULTADOS E DISCUSSÃO}

\subsection{Caracterização Físico-Química da CMS de Tilápia do Nilo in natura e Análise Elementar}

Na caracterização físico-química da CMS de Tilápia do Nilo in natura obteve-se os

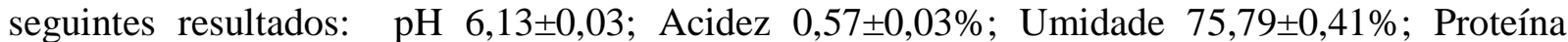

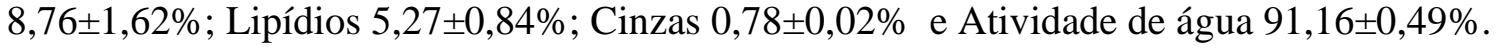

Após a secagem e o desengorduramento da CMS, realizou-se a análise elementar. Obtevese como valores de Carbono de 56,02 \% para a CMS bruta. Em relação ao teor de proteína, obteve-se 70,11\%. Estes valores de percentual de proteína foram utilizados como referência para o cálculo das propriedades hidrofílicas das amostras nas próximas etapas.

\subsection{Perfil de hidrólise enzimática (GH) da CMS bruta}

A Figura 1 mostra o perfil de hidrólise obtido para a amostra de CMS bruta. Verifica-se na a amostra apresenta GH nos primeiros 30 minutos de hidrólise. Os valores obtidos foram superiores ao estudo realizado por Zavareze (2009) que utilizou polpa de Cabrinha, a enzima Flavourzyme ${ }^{\circledR}$, obtendo um GH para 30 minutos e 60 minutos de 22,08 \%, 23,68\% respectivamente. A análise estatística mostrou diferença significativa $(\mathrm{p}<0,05)$ nos resultados de GH para 60 minutos $(33,95 \pm 6,98 \%)$ e 300 minutos $(58,98 \pm 3,76 \%)$, sendo, portanto, estas amostras utilizadas nas próximas etapas do estudo. 


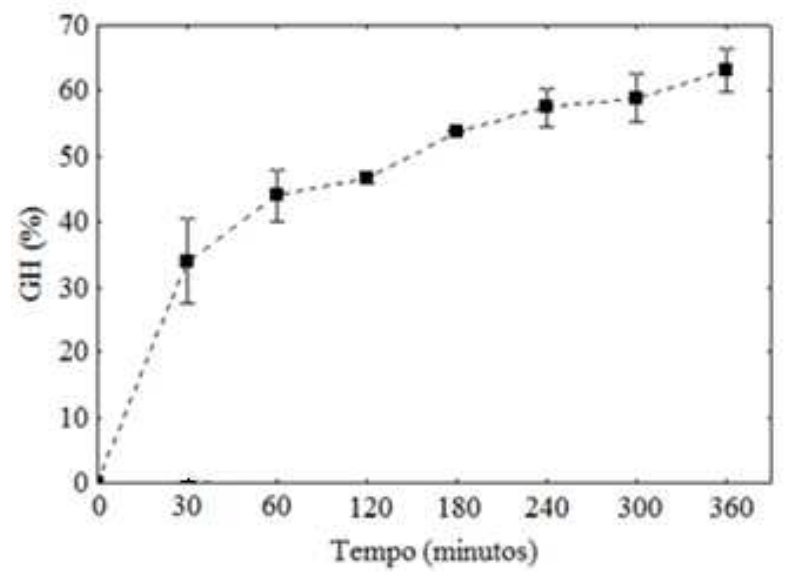

Figura 1 - Perfil de hidrólise (GH) da CMS bruta ao longo do tempo utilizando Flavourzyme ${ }^{\circledR}$

\subsection{Propriedades Funcionais Hidrofílicas da CMS Bruta e Hidrolisada em Diferentes Tempos}

A Tabela 1 mostra as médias de solubilidade em diferentes pHs das amostras de CMS bruta e que não passou pelo processo de hidrólise (C), hidrolisada durante 60 minutos (H60) e hidrolisada em 300 minutos (H300). Comparando-se entre as amostras, observa-se que apenas para o $\mathrm{pH} 11$ houve diferença significativa $(\mathrm{p}<0,05)$ para a solubilidade da amostra $\mathrm{H} 300$, sendo este valor de solubilidade superior aos demais. O mesmo ocorre quando se compara os resultados da solubilidade nos diferentes pHs para uma mesma amostra. Os resultados de solubilidade dos hidrolisados enzimáticos estão próximos aos encontrados por Zavareze (2009) encontrou uma faixa de 25 a $35 \%$ para hidrolisado de Cabrinha obtido com a enzima Flavourzyme ${ }^{\circledR}$ na faixa de pH de 3,0-11,0, sendo os resultados obtidos no presente estudo de acordo com o esperado, podendo, portanto, ser utilizado CMS de Tilápia do Nilo hidrolisado nas condições testadas em alimentos onde a solubilidade seja requerida.

Tabela 1 - Médias de solubilidade em diferentes pHs das amostras de CMS bruta (C), hidrolisada durante 60 min (H60) e hidrolisada em 300 min (H300)

\begin{tabular}{|c|c|c|c|c|}
\hline \multirow{2}{*}{$\begin{array}{c}\text { Amostra de } \\
\text { CMS }\end{array}$} & \multicolumn{4}{|c|}{ Solubilidade (\%) } \\
\hline & $\mathrm{pH} 3$ & pH 5 & $\mathrm{pH} 7$ & $\mathrm{pH} 11$ \\
\hline $\mathrm{C}$ & $46,93^{\mathrm{aA}} \pm 5,50$ & $40,28^{\mathrm{aA}} \pm 1,75$ & $39,25^{\mathrm{aA}} \pm 1,50$ & $45,01^{\mathrm{aA}} \pm 2,68$ \\
\hline H60 & $34,75^{\mathrm{aA}} \pm 6,32$ & $36,44^{\mathrm{aA}} \pm 7,17$ & $29,13^{\mathrm{aA}} \pm 2,81$ & $42,13^{\mathrm{aA}} \pm 6,26$ \\
\hline $\mathrm{H} 300$ & $32,78^{\mathrm{aA}} \pm 0,42$ & $37,70^{\mathrm{aA}} \pm 4,92$ & $30,11^{\mathrm{aA}} \pm 3,65$ & $66,51^{\mathrm{bB}} \pm 5,62$ \\
\hline
\end{tabular}

Médias seguidas de letras minúsculas diferentes, nas colunas, diferem em nível de $95 \%$ de confiabilidade $(\mathrm{p}<0,05)$ pelo Teste de Tukey. Médias seguidas de letras maiúsculas diferentes, nas linhas, diferem em nível de $95 \%$ de confiabilidade $(\mathrm{p}<0,05)$ pelo Teste de Tukey.

Os resultados obtidos para a CRO e os parâmetros de cor estão mostrados na Tabela 2. 
Tabela 2 - Médias da Capacidade de Retenção de Óleo e parâmetros de cor para as amostras de CMS bruta (C), hidrolisada durante 60 min (H60) e hidrolisada em 300 min (H300)

\begin{tabular}{lcccc}
\hline \multicolumn{1}{c}{$\begin{array}{c}\text { Amostra de } \\
\text { CMS }\end{array}$} & $\begin{array}{c}\text { CRO } \\
\text { (mL óleo/g amostra) }\end{array}$ & L $^{*}$ & $\mathrm{a}^{*}$ & $\mathrm{~b}^{*}$ \\
\hline C & $2,73^{\mathrm{a}} \pm 0,71$ & $18,80^{\mathrm{a}} \pm 2,45$ & $6,78^{\mathrm{a}} \pm 0,26$ & $18,54^{\mathrm{a}} \pm 0,77$ \\
H60 & $3,10^{\mathrm{a}} \pm 0,10$ & $23,71^{\mathrm{a}} \pm 2,94$ & $10,12^{\mathrm{b}} \pm 0,52$ & $27,64^{\mathrm{b}} \pm 0,82$ \\
H300 & $2,50^{\mathrm{a}} \pm 0,10$ & $21,96^{\mathrm{a}} \pm 1,38$ & $9,78^{\mathrm{b}} \pm 0,86$ & $28,30^{\mathrm{b}} \pm 1,91$ \\
\hline
\end{tabular}

CRO é a Capacidade de retenção de óleo. Médias seguidas de letras diferentes, nas colunas, diferem em nível de 95 $\%$ de confiabilidade $(\mathrm{p}<0,05)$ pelo Teste de Tukey.

Observa-se que em relação a CRO, a hidrólise não exerceu influência, pois não se verifica diferença significativa $(\mathrm{p}>0,05)$ em relação a amostra que não passou pelo processo de hidrólise. $\mathrm{O}$ mesmo ocorre com o parâmetro $\mathrm{L}^{*}$. Para os parâmetros de cor $\mathrm{a}^{*} \mathrm{e} \mathrm{b}^{*}$, ocorre diferença significativa $(\mathrm{p}<0,05)$ entre a amostra $\mathrm{C}$ e as amostras $\mathrm{H} 60$ e $\mathrm{H} 300$, havendo um aumento nos valores destes parâmetros em relação à amostra $\mathrm{C}$.

Sathivel et al. (2005) observaram que para a proteína hidrolisada de salmão, a capacidade de retenção de óleo durante a hidrólise aumentou para um certo intervalo de tempo e depois houve uma diminuição em hidrólise mais prolongada. $\mathrm{O}$ valor máximo encontrado para a $\mathrm{CRO}$ foi de 7,8 mL de óleo/g de proteína, aos 50 minutos de hidrólise usando Palatase a uma proporção de $0,5 \%$ a $50{ }^{\circ} \mathrm{C}$, diminuindo para $4,3 \mathrm{~mL}$ de óleo/g de proteína quando a hidrólise foi estendida para 75 minutos. Os resultados obtidos no presente estudo são inferiores aos valores encontrados no trabalho anteriormente citado, porém, pode ser justificado pela hidrólise excessiva ou pela exposição de grupos hidrofílicos durante a hidrólise enzimática. Esta propriedade tal como apresentada pode ser benéfica para alimentos com menor incorporação de óleos.

A hidrólise excessiva pode comprometer a integridade da estrutura da proteína, resultando na degradação da rede de proteínas que aprisiona o óleo (He et al., 2013). Os resultados obtidos para CRO para o C, H60 e H300, não diferiram significativamente entre si, sendo que resultados semelhantes foram encontrados para hidrolisado de carne de Tilápia fresca picada, onde a CRO de $3,07 \mathrm{ml} / \mathrm{g}$ para a Flavourzyme ${ }^{\circledR}$ e para Alcalase foi de $2,27 \mathrm{ml} / \mathrm{g}$ (Foh et al., 2010).

Em estudo para três amostras de hidrolisados de carpa capim, realizado por Wasswa et al. (2007), com GH de 5,02; 10,4 e 14,9; Resultados semelhantes ao estudo foram encontrados para o parâmetro b*, sendo 18,$4 ; 22,0$ e 26,6 , para parâmetro $L^{*}$ valores de 68,$9 ; 59,6$ e 59,3 e para o parâmetro a* $-3,73 ;-2,46$ e $-1,38$.

$\mathrm{Na}$ Tabela 3 estão mostrados os resultados da CAA CMS bruta (C), hidrolisada durante 60 min (H60) e hidrolisada em 300 min (H300), para diferentes valores de pH. Os valores de CAA para a amostra H60 não apresentou diferença estatística quando se compara entre os pHs. Já para a amostra H300, a CAA em pH 3 diferiu estatisticamente $(\mathrm{p}<0,05)$ da CAA em pH 11, sendo para a última um valor superior. Comparando-se as amostras hidrolisadas com a amostra $\mathrm{C}$, para 


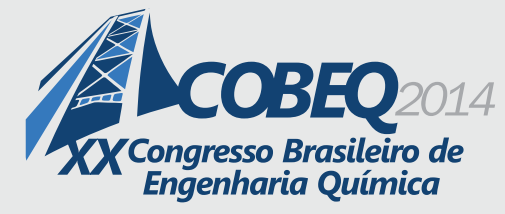

19 a 22 de outubro de 2014

Florianópolis/SC

um mesmo $\mathrm{pH}$, observa-se que para $\mathrm{pH} 5$ ocorre diferença significativa entre $\mathrm{C}$ e as demais amostras, sendo que a hidrólise aumentou a capacidade de absorção de água da CMS. Em pH 11, ocorre diferença estatística entre a amostra $\mathrm{H} 300$ e a $\mathrm{C}$, sendo que a mesma característica é observada, o aumento da CAA para a amostra hidrolisada durante 300 minutos.

Tabela 3 - Médias da Capacidade de Absorção de Água (CAA) em diferentes pHs das amostras de CMS bruta (C), hidrolisada durante 60 min (H60) e hidrolisada em 300 min (H300)

\begin{tabular}{lcccc}
\hline \multicolumn{1}{c}{ Amostra de } & \multicolumn{4}{c}{ CAA (\%) } \\
\cline { 2 - 5 } \multicolumn{1}{c}{ CMS } & $\mathrm{pH} 3$ & $\mathrm{pH} \mathrm{5}$ & $\mathrm{pH} \mathrm{7}$ & $\mathrm{pH} 11$ \\
\hline $\mathrm{C}$ & $272,95^{\mathrm{aA}} \pm 5,73$ & $272,07^{\mathrm{aA}} \pm 9,65$ & $297,17^{\mathrm{aB}} \pm 9,22$ & $297,77^{\mathrm{aB}} \pm 1,51$ \\
$\mathrm{H} 60$ & $289,10^{\mathrm{aA}} \pm 4,52$ & $312,99^{\mathrm{bA}} \pm 5,65$ & $307,47^{\mathrm{aA}} \pm 19,14$ & $311,24^{\mathrm{abA}} \pm 9,76$ \\
$\mathrm{H} 300$ & $291,78^{\mathrm{aA}} \pm 7,66$ & $301,20^{\mathrm{bAB}} \pm 5,33$ & $308,29^{\mathrm{aAB}} \pm 1,80$ & $317,84^{\mathrm{bB}} \pm 6,91$ \\
\hline
\end{tabular}

Médias seguidas de letras minúsculas diferentes, nas colunas, diferem em nível de $95 \%$ de confiabilidade $(\mathrm{p}<0,05)$ pelo Teste de Tukey. Médias seguidas de letras maiúsculas diferentes, nas linhas, diferem em nível de $95 \%$ de confiabilidade $(\mathrm{p}<0,05)$ pelo Teste de Tukey.

Foh et al. (2010), para hidrolisado de carne de Tilápia fresca picada (GH de 2,5\%) encontraram uma capacidade de absorção de água igual a $2,77 \mathrm{~mL} / \mathrm{g}$ ou o equivalente a $277 \%$ e em mesmo estudo para hidrolisado de carne de Tilápia mergulhada em água quente (GH de 12,5 $\%$ ) uma CAA de $2,10 \mathrm{~mL} / \mathrm{g}$, valores próximos aos encontrados no presente estudo. Zavareze et al. (2009), obtiveram para hidrolisado utilizando Flavourzyme ${ }^{\circledR}$ (concentração substrato/tampão de $1 \mathrm{~g} / \mathrm{mL}, 2 \%$ de enzima/substrato, $\mathrm{pH} 7$ durante 60 minutos a $40^{\circ} \mathrm{C}$ ) de cabrinha nos $\mathrm{pHs}$ de 3,0-11,0 CAAs variaram de 8,5 a $10 \mathrm{~mL}$ de água/g de proteína ou 85 a $100 \%$, valores inferiores ao encontrado para toda a faixa de $\mathrm{pH}$ do presente estudo. Os resultados obtidos para a CAA demonstram a potencialidade do uso de CMS de Tilápia em produtos onde esta propriedade é requerida, como produtos da indústria cárnea, que utiliza diversos insumos que potencializam a retenção de água.

\section{CONCLUSÃO}

No presente estudo fez-se a hidrolise de CMS de Tilápia do Nilo utilizando Flavourzyme®. Os resultados do $\mathrm{GH}$ apresentaram diferença para os tempos de 60 minutos e 300 minutos, correspondendo a 33,95\% e 58,98 \%, respectivamente. Para a solubilidade, apenas a amostra hidrolisada durante 300 minutos e em pH 11 apresentou diferença significativa. Para a CAA, nos pHs 5 e 11, houve diferença entre as amostras controle e os hidrolisados. Para a CRO, não houve diferença entre as amostras. Quanto aos parâmetros de cor, apenas a* e b* apresentaram diferença significativa entre o controle e os hidrolisados, sendo os últimos com valor superior. Os resultados apresentaram-se satisfatórios, visto que algumas propriedades importantes não foram alteradas, possibilitando o emprego da proteína hidrolisada em matrizes alimentares, como pães, biscoitos, "hamburguers" e outros produtos cárneos, sem modificação das suas principais características tecnológicas, possibilitando assim o emprego de proteína de maior digestibilidade.

\section{REFERÊNCIAS}




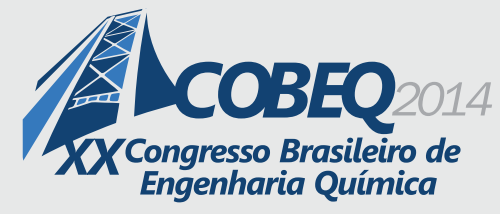

BOSCOLO, W. R.; HAYASHI, C.; SOARES, C.M.; FURUYA, W.M.; MEURER, F. Desempenho e características de carcaça de machos revertidos de Tilápia do Nilo (Oreochromis niloticus), linhagens tailandesa e comum, nas fases inicial e de crescimento. R. Bras. Zootec., v. 30:5, p. 1391-1396, 2001.

CÂNDIDO, L.M.B.; SGARBIERI, V.C. Enzymatic hydrolysis of Nile tilapia (Oreochromus niloticus) muofibrillar proteins: effects on nutritional and hydrophilic properties. J. Sci. Food Agr., v. 83, p. 937-944, 2003.

CHALAMAIAH, M.; DINESH KUMAR, B.; HEMALATHA, R.; JYOTHIRMAYI, T. Fish protein hydrolysates: Proximate composition, amino acid composition, antioxidant activities and application: A review. Food Chem., v. 135, p. 3020-3038, 2012.

FOH, M.B.K.; AMADOU, I.; FOH, B.M.; KAMARA, M. T.; XIA, W. Functionality and Antioxidant Properties of Tilapia (Oreochromis niloticus) as Influence by the Degree of Hydrolysis. Int. J. Mol. Sci., v. 11, p. 1850-1869, 2010.

INSTITUTO ADOLFO LUTZ. Normas Analíticas do Instituto Adolfo Lutz. Métodos químicos e físicos para análise de alimentos, São Paulo: IMESP, 1985.

LIU, Q.; KONG, B.; XIONG, Y.L.; XIA, X. Antioxidant activity and functional properties of porcine plasma protein hydrolysate as influenced by the degree of hydrolysis. Food Chem., v.118, p.403-410, 2010.

MAIA, E. L. Otimização de metodologia para caracterização de constituintes lipídicos e determinação da composição em ácidos graxos e aminoácidos de peixes de água doce. Tese de Doutorado. FEA/Unicamp, Campinas, SP. 1992.

OGAWA, M.; MAIA, E.L. Manual da Pesca. Ciência e Tecnologia do Pescado. São Paulo: Livraria Varela, 1999.

PANYAM, D., KILARA, A. Enhancing the functionality of food proteins by enzymatic modification. Trends Food Sci Tech., v.7:4, 120-125, 1996.

SANTOS, S.D’A.; MARTINS, V.G.; MELLADO, M.S.; HERNÀNDEZ, C.P. Otimização dos parâmetros de produção de hidrolisados protéicos enzimáticos utilizando pescado de baixo valor comercial. Quím Nova, v.32:1 p.72-77, 2009.

SATHIVEL, S., SMILEY, S., PRINYAWIWATKUL, W., BECHTEL, P. J. Functional and nutritional properties of red salmon (Oncorhynchus nerka) enzymatic hydrolysates. J Food Sci, v. 70:6, p.401-406, 2005.

SCHMIDT, C.G.; SALLAS-MELLADO, M. Influência da ação das enzimas alcalase e Flavourzyme no grau de hidrólise das proteínas de carne de frango. Quím Nova, v.32:5, p.1144-1150, 2009

SIMÕES, M.R.; RIBEIRO, C.F.A.; RIBEIRO,S.C.A.; PARK,K.J.; MURR,F.E.X. Composição físico-química, microbiológica e rendimento do filé de Tilápia tailandesa (Oreochromis niloticus). Ciênc Tecnol Aliment. v.27:3, p. 608-613. 2007.

SOUZA, M. L. R. Comparação de Seis Métodos de Filetagem, em Relação ao Rendimento de Filé e de Subprodutos do Processamento da Tilápia-do-Nilo (Oreochromis niloticus). R. Bras. Zootec., v. 31:3, p. 1076-1084. 2002.

VIDAL, J.M.A.; RODRIGUES, M.C.O.; ZAPATA, J.F.F.; VIEIRA, M.M. Concentrado protéico de resíduos da filetagem de Tilápia-do-nilo (Oreochromis niloticus): caracterização físico-química e aceitação sensorial. Rev. Ciênc. Agron. v. 42:1, p. 92-99, 2011.

VISENTAINER, J. V.; GOMES, S.T.; HAYASHI, C.; SANTOS-JÚNIOR, O. O.; SILVA, A. B. M.; JUSTI, K. C. SOUZA, N. E.; MAKOTO, M. Efeito do tempo de fornecimento de ração suplementada com óleo de linhaça sobre a composição físico-química e de ácidos graxos em cabeças de Tilápia do Nilo (Oreochromis niloticus). Ciênc Tecnol Aliment., v.23:3, p. 478-484, 2003.

WANG, S.H.; ROCHA, G.O.; NASCIMENTO, T.P.; ASCHERI, J.L.R. Absorção de água e propriedades espumantes de farinhas extrusadas de trigo e soja. Ciênc Tecnol Aliment., v.26:2, p.475-481, 2006.

WASSWA, J.; TANG, J.; GU, X.; YUAN, X. Influence of the extent of enzymatic hydrolysis on the functional properties of protein hydrolysate from grass carp (Ctenopharyngodon idella) skin. Food Chem., v.104, p. 16981704, 2007.

ZAVAREZE, E.R.; SILVA, C.M., MELLADO, C.S.; HERNÁNDEZ, C.P. Funcionalidade de hidrolisados proteicos de cabrina (Prionotus punciatus) obtidos a partir de diferentes proteases microbianas. Quím Nova, v.32:7, p.17391743, 2009. 